\title{
Tecnologia de sementes na emergência e variáveis biométricas da Flor de Seda
}

\section{(Calotropis procera)}

\author{
Seed technology in emergence and biomectric variables of the Silk Flower (Calotropis procera) \\ Tecnología de semillas en emergência y variables biométricas de Silk Flower (Calotropis procera)
}

Recebido: 17/12/2021 | Revisado: 26/12/2021 | Aceito: 30/12/2021 | Publicado: 31/12/2021

Cristovam Colombo Belfort

ORCID: https://orcid.org/0000-0001-8963-7179 Universidade Federal do Piaú, Brasil

E-mail: ccbelfort@yahoo.com.br

Pedro Emartino Bezerra Campelo

ORCID: https://orcid.org/0000-0002-9180-6178 Universidade Federal do Piauí, Brasil

E-mail: pedroemartino_campelo@hotmail.com

Flávia da Silva Soares

ORCID: https://orcid.org/0000-0002-4454-8321 Universidade Federal do Piauí, Brasil

E-mail: flaviasoares@ufpi.edu.br

Antonio Pereira de Queiroz Neto

ORCID: https://orcid.org/0000-0002-5177-5194

Universidade Federal do Piauí, Brasil

E-mail: agroufpi23queiroz@gmail.com

Eulina Barbosa Nery

ORCID: https://orcid.org/0000-0002-7476-1131

Universidade Federal do Piauí, Brasil

E-mail: eulinabarbosanery@gmail.com

Kássio Felipe Bezerra Oliveira

ORCID: https://orcid.org/0000-0001-8480-9808

Universidade Federal do Piauí, Brasil

E-mail: kassiolipe@gmail.com

\begin{abstract}
Resumo
A flor de seda (Calotropis procera) é uma espécie conhecida como invasora, tolerante a ambiente adverso, nativa da África e do sudoeste asiático e popularizada no Brasil como Ciúme, Saco de Velho, Paina e Flor de Seda. Destacada pelo uso como forrageira, medicinal e até na indústria têxtil, ainda necessita de estudos que viabilizem seu cultivo comercial. Objetivou-se avaliar os efeitos da secagem e reidratação das sementes na emergência e seu crescimento inicial, em trabalho conduzido entre setembro e outubro de 2018. O delineamento foi blocos ao acaso, com 04 repetições e os tratamentos consistiram do arranjo fatorial $2 \times 5$, sendo o primeiro fator a condição da semente no plantio (recém colhida ou desidratada por 48 horas) e o segundo a hidratação (00, 02, 04,06 e 08 horas). Em cada situação realizaram-se determinações de ganho e perda de umidade. Sementes recém colhidas apresentam teor de umidade em torno de $70 \%$ e desidratadas próximo de $35 \%$. Quando reidratadas, ainda ocorre, nos dois casos, ganho de umidade respectivamente de 18,13 e $43,33 \%$. A reidratação melhora o vigor das sementes recém colhidas não influindo nas desidratadas e não interferindo na emergência total que atinge $90 \%$. A secagem não influi na profundidade da raiz, mas reduz drasticamente altura, peso da matéria fresca da parte aérea e raiz entre 27 e $210 \%$.

Palavras-chave: Planta industrial; Secagem e reidratação de sementes; Vigor de sementes; Ecofisiologia.
\end{abstract}

\begin{abstract}
The silk flower (Calotropis procera) is an invasive species known as tolerant to adverse environment, native to Africa and southwestern Asia and popularized in Brazil as Jealousy, Old Bag, Kapok Flower and Silk. Highlighted by the use as forage, medicinal and even in the textile industry still requires studies that allow commercial cultivation. This work aimed to evaluate the effects of drying and rehydration of seed emergence and initial growth, in a study conducted between September and October 2018. The experimental design was a randomized block design with 04 replications and treatments consisted of $2 \times 5$ factorial arrangement, the first factor being the condition of the seed at planting (freshly picked or dried for 48 hours) and the second hydration (00, 02, 04, 06 e 08 hours). In each situation determinations were performed gain and loss of moisture. Fresh seeds have moisture content of around $70 \%$ and around 35\% dehydrated. When rehydrated, still occurs in both cases, moisture gain respectively 18.13 and $43.33 \%$. Rehydration improves the vigor of fresh seeds not influencing the dehydrated and not interfering with emergency total
\end{abstract}


reaches $90 \%$. Drying does not affect the depth of the root, but dramatically reduces the time, fresh weight of shoot and root between 27 and $210 \%$.

Keywords: Industrial plant; Seed drying and rehydration; Seed strength; Ecophysiology.

\section{Resumen}

La flor de seda (Calotropis procera) es una espécie conocida como invasora, tolerante al ambiente adverso, originaria de África y el sudeste asiático y popularizada em Brasil como Celos, Saco de Velho, Paina y Flor de Seda. Destacado por su uso como forrajero, medicinal e incluso en la indústria têxtil, aún necessita estúdios para viabilizar su cutivo comercial. El objetivo fue avaluar los efectos del secado y rehidratación de semillas en emergencia y su crecimiento inicial, en un trabajo realizado entre septiembre y octubre de 2018. El diseño fue de bloques al azar, com 04 repetiociones y los tratamientos consistieron en un factorial 2 x 5 disposición, siendo el primer fator el estado de la semilla en el momento de la siembra (recién cosechada o deshidratada durante 48 horas) y el segundo la hidratación (00, 02, 04, 06 y 08 horas). En cada situación, se realizaron determinaciones de ganancia y perdida de humedad. Las semillas recién cosechadas tienen un contenido de humedad de alrededor del $70 \%$ y se deshidratan alrededor del $35 \%$. Cuando se rehidrata en ambos casos todavía hay una ganancia de humedad del 18,13 y 43,33\% respectivamente. La rehidratación mejora el vigor de las semillas recién cosechadas, no influyendo en las deshidratadas y no interfiriendo con la emergencia total, que alcanza el $90 \%$. El secado no influye em la profundidad de las raíces entre um 27 y un $210 \%$.

Palabras clave: Planta industrial; Secado y rehidratación de semillas; Fuerza de la semilla; Ecofisiología.

\section{Introdução}

A espécie Calotropis procera é uma planta arbustiva, de pequeno porte, pertence à família Apocynaceae, distribuída pelas regiões tropicais e subtropicais de todo o mundo. Nativa da África, Península Arábica e Sudoeste da Ásia, encontra-se atualmente naturalizada na Áustria, em muitas ilhas do Pacífico, nas Ilhas do Caribe e na América Central e do Sul (Moreira Filho \& Viana, 2007).

Segundo o Instituto Hórus (2012), foi introduzida no Brasil como planta ornamental em 1900, e disseminou-se por todo o País, adaptando-se facilmente às regiões semiáridas, passando a se comportar como invasora de áreas de pastagens, formando populações numerosas à margem das vias de transporte, sendo encontrada em vários Estados da Região Nordeste, além dos Estados de Minas Gerais, São Paulo, Espírito Santo, Mato Grosso, Rio de Janeiro, Goiás e no Distrito Federal (Vaz et al., 1998). É conhecida por Algodão de Seda, Flor de Seda, Algodão da Praia, Leiteira, Paina-de-pó, Paina-de-Seda, Saco-deVelho, Queimadeira, Pé-de-Balão, Janaúba e Ciúme (Souto et al., 2008). A agressividade desta espécie continua motivando pesquisadores a avaliar seu potencial invasor e fornecer subsídio para a elaboração de um plano de manejo para a erradicação da mesma na Restinga do Xexé, no Estado do Rio de Janeiro, conforme estudos de Rangel \& Nascimento (2011).

Com ampla utilização, salienta-se na produção de biomassa para o arraçoamento animal pela expressiva quantidade de proteína e outros componentes (Vaz, et al., 1998), sendo utilizada para a produção de feno em substituição parcial do concentrado visando a produção de leite de cabra (Fernandes Jr., 2008). Seu desempenho como forrageira se impõe no semiárido, tendo em vista a duração da área foliar, garantindo a permanência das folhas durante os períodos mais críticos de estresse hídrico, rebrotando vigorosamente diante do manejo de cortes, produzindo grande quantidade de sementes, além de apresentarem reconhecida tolerância a solos salinos (Rocha et al., 2007). Complementarmente apresenta diversa aplicação como fitoterápico (Khan; Malik 1989; Aktar et al. 1992; Arya \& Kumar, 2005). Os filamentos sedosos aderidos às sementes, estruturas utilizadas para dispersão natural da espécie, dadas as propriedades físico-químicas das suas fibras, podem ser aproveitados para a confecção de tecidos finos ou outros tipos de produtos de qualidade na indústria têxtil, conforme consta na descrição do patenteamento de uma tecnologia registrada no INPI em 2007, abrindo espaço para a substituição da matéria prima universalmente conhecida, oriunda do bicho da seda.

Apresenta uma ou poucas hastes cilíndricas e ramificações, hábito ereto, folhas alternas, com as partes mais jovens destes órgãos, inclusive pedúnculos e frutos recobertos por cerosidade (Rangel \& Nascimento, 2011). O corte do caule e folhas provoca um fluxo abundante de látex em decorrência do rompimento dos tecidos, característica que bem identifica esta família 
botânica, secreção esta que representa um mecanismo de defesa contra predadores, vários microrganismos ou insetos (Moreira Filho \& Viana, 2007).

É oportuno acrescentar a multiplicidade de uso desta espécie, onde a presença de atividades enzimáticas no látex pode confirmar seu envolvimento no controle de fitopatógenos e insetos, principalmente em suas folhas onde o látex circula abundantemente (Ramos et al., 2006; Freitas et al., 2007). Constitui-se, pois, em mais uma alternativa para o aproveitamento industrial no âmbito do agronegócio, particularmente no controle de fitomoléstias (Kareem; Akpan \& Ojo, 2008)

O florescimento e frutificação dessa planta ocorrem durante o ano todo, com uma produção de centenas de milhares de sementes/plantas/ano (Little et al., 1974), podendo a sua propagação ser realizada por processo vegetativo ou por via seminífera. Segundo os mesmos, as sementes germinam com relativa facilidade, tanto é que verificaram germinação de $89 \%$ entre 7 e 64 dias após a semeadura, sofrendo, porém, decisiva influência do tipo de substrato (Carvalho \& Nakagawa, 2000; Silva et al., 2009), muito embora se constate grande irregularidade.

A produção de sementes de qualidade impõe a realização da colheita no momento mais próximo possível da maturidade fisiológica (Garcia et al., 2004), condição em que as mesmas, para atingi-la, passam por transformações morfológicas, fisiológicas que se iniciam no momento da fertilização do óvulo e concluem com o acúmulo máximo de matéria seca (Popinigis, 1985). De um modo geral, nesta ocasião alcançam teores de água superiores a 30\%, nível inadequado para a colheita mecânica (Peske \& Barros, 1997; Miranda et al.,1999).

A qualidade das sementes decresce a partir da maturidade fisiológica, em função de inúmeras variáveis do meio ambiente. Deste modo a secagem é fundamental na produção de sementes de alta qualidade, pois permite a redução do teor de água em níveis adequados para o armazenamento (Baudet et al., 1999)

É conhecido que as sementes com baixo conteúdo de água sofrem aumento na lixiviação de solutos ao serem submetidas à rápida hidratação, devido à transição imediata da fase gel para líquido-cristalino dos fosfolipídios da membrana, durante a embebição (Corrêa \& Afonso Junior, 1999). Conforme atesta Lin (1990), esta situação poderá provocar danos às sementes, ocasionando plântulas anormais e até ausência total de germinação. Com idêntico raciocínio sementes secas semeadas em solo muito úmido podem absorver água rapidamente, não havendo tempo hábil para a reorganização das tais membranas (Vieira et al., 2004).

Em sementes de soja o aumento do teor de água inicial contribui para a redução dos danos provocados pela embebição rápida, tendo em vista que as membranas da semente já se encontram no estado cristalino líquido e, assim, podem tolerar o influxo rápido de água (Rossetto et al., 1997; Rosa et al., 2000). A interação entre o teor de água inicial das sementes e a temperatura de embebição é fator determinante para a ocorrência de alterações permanentes ou transitórias na estrutura das membranas celulares (Costa et al, 2008). Assim, mecanismos naturais ou artificiais podem ser concebidos na perspectiva de impedir ou minimizar o dano por embebição, resultante da rápida reidratação dos tecidos quando as sementes são colocadas para germinar.

O condicionamento osmótico é um procedimento operacional importante para regularizar a emergência e consiste da hidratação controlada das sementes, suficiente para promover atividades pré-metabólicas sem, contudo, permitir a emissão da raiz primária (Heydecker et al., 1973). Os efeitos do condicionamento osmótico de sementes de várias espécies incluem a emergência mais rápida e uniforme das plântulas e a redução no tempo de germinação no campo e em laboratório. Esse tratamento tem sido utilizado em diferentes espécies com o objetivo de aprimorar o desempenho de lotes de sementes e o estabelecimento de plantas, principalmente em condições adversas de ambiente (Nascimento, 1998).

Sendo a Flor de Seda uma planta em fase de domesticação e, considerando ainda, a necessidade de estudar o seu comportamento, sobretudo, em aspectos que envolvam a etapa de formação da cultura no campo, buscou-se com esta pesquisa, avaliar a influência da secagem e reidratação das sementes, de modo a harmonizar a emergência. 


\section{Metodologia}

A pesquisa em tela pode ser classificada quanto ao tipo de abordagem em quantitativa, e quanto aos procedimentos, é considerada experimental, segundo observações de Gil (2008) referência metodológica adotada. Foi executada em viveiro coberto com sombrite preto com 50\% de sombreamento, no Departamento de Fitotecnia da Universidade Federal do Piauí, em Teresina, no período de setembro a outubro de 2018, com Flor de Seda, material colhido de plantas mantidas na área experimental.

Estudaram-se os efeitos do tratamento das sementes em diferentes níveis de hidratação com adoção do desenho experimental de blocos ao acaso, com 04 repetições e os tratamentos consistiram do arranjo fatorial $2 \times 5$, sendo o primeiro fator a condição da semente na ocasião do plantio (recém colhida; recém colhida e desidratada por 48 horas) e o segundo fator a hidratação (00, 02, 04, 06 e 08 horas). Em cada situação as sementes foram pesadas para a determinação da quantidade de água absorvida, conforme metodologia descrita em Brasil (2009). Os lotes definidos para desidratação foram colocados em bacias plásticas e deixados para secagem natural nas bancadas do laboratório de sementes do Departamento de Fitotecnia do Centro de Ciências Agrárias da UFPI por um lapso de tempo de 48 horas. Foram determinados os teores de umidade em amostras de 40 sementes recém colhidas e, posteriormente nas desidratadas, dados não submetidos à análise estatística. Para quantificar os efeitos dos tratamentos foram determinados emergência inicial e final, altura da planta medida do colo à gema terminal, comprimento da raiz, peso da matéria fresca da parte aérea e da raiz quando as plantas apresentaram entre 02 e 04 folhas verdadeiras, cerca de 35 dias após a semeadura.

\section{Resultados e Discussão}

\section{Emergência}

A emergência inicial medida aos seis dias da semeadura em sementes recém colhidas não submetidas à hidratação foi muita baixa $(8,81 \%)$, quando comparadas às sementes desidratadas e expostas às condições similares conforme é mostrado na Tabela 1.

Tabela 1 - Valores médios de emergência inicial e final para sementes recém colhidas e desidratadas, com diferentes tempos de hidratação de Flor de Seda (Calotropis procera) Teresina/Piaui, 2018.

\begin{tabular}{c|c|c|c|c|c}
\hline \multirow{2}{*}{ Tipo de semente } & \multicolumn{5}{|c}{ Hidratação (horas) } \\
\cline { 2 - 6 } & 00 & 02 & 04 & 06 & 08 \\
\cline { 2 - 6 } & \multicolumn{5}{|c}{ Inicial } \\
\hline Recém colhida & $8,81 \mathrm{bB}$ & $43,18 \mathrm{aAB}$ & $54,56 \mathrm{aA}$ & $75,31 \mathrm{aA}$ & $75,31 \mathrm{aA}$ \\
\hline Desidratada & $40,62 \mathrm{aA}$ & $59,37 \mathrm{aA}$ & $53,12 \mathrm{aA}$ & $56,25 \mathrm{aA}$ & $31,25 \mathrm{bA}$ \\
\hline & \multicolumn{5}{|c}{ Final } \\
\hline Recém colhida & $90,62 \mathrm{aA}$ & $90,62 \mathrm{aA}$ & $87,50 \mathrm{aA}$ & $90,62 \mathrm{aA}$ & $90,62 \mathrm{aA}$ \\
\hline Desidratada & $90,62 \mathrm{aA}$ & $100,00 \mathrm{aA}$ & $96,87 \mathrm{aA}$ & $96,87 \mathrm{aA}$ & $87,50 \mathrm{aA}$ \\
\hline
\end{tabular}

Médias seguidas de mesma letra minúscula na coluna e maiúscula na linha, não diferem entre si, ao nível de 5\% de probabilidade, pelo Teste de Tukey. Fonte: Elaborada pelos autores, UFPI, Teresina-PI (2018).

Os resultados atestam que o responsável pelo baixo índice verificado não pode ser atribuído à umidade, tendo em vista o elevado valor encontrado, cerca de $71,00 \%$, até porque, as sementes desidratadas continham cerca de $35,72 \%$ de água no mesmo momento e o nível de emergência para as últimas foi de 40,62\%. Isto pode demonstrar que as estruturas estavam preparadas para a perpetuação da espécie independentemente se, recém colhidas ou não. É provável que tais valores possam ser creditados principalmente à presença de inibidores presentes na semente, mecanismo de proteção natural, mencionados por 
Chin et al., (1989) que, uma vez removidos propiciaram a elevação no nível de emergência (Tabela 1). Vale acentuar que em muitos casos o fator responsável pela dormência em sementes é a presença de substâncias inibidoras, que exercem um efeito antagônico ao GA3 (Taiz \& Zeiger, 1998; Atencio et al., 2003), o que bem justifica o uso da pré-hidratação ou a simples lavagem em água corrente, algo às vezes mais eficiente que a própria aplicação do GA3 (Atencio et al., 2003).

De qualquer modo é importante salientar a influência da hidratação das sementes nas seis primeiras horas, elevando a emergência inicial. Os resultados dos testes de vigor são mais eficientes que o teste de germinação, inclusive para detectar pequenas modificações fisiológicas ocorridas nas sementes submetidas aos distintos tempos de embebição parcial ou condicionamento hídrico (Queiroga et al., 2009). Os autores também verificaram que o condicionamento hídrico foi mais efetivo para incrementar o vigor das sementes de algodão, mas não foi eficiente para elevar seu potencial germinativo.

Quanto às sementes desidratadas, estas não reeditaram os resultados obtidos para sementes recém colhidas, muito embora a umidade final possa ter sido recuperada. Tudo faz parecer que a desidratação tenha promovido a indução de quiescência e este seja o mecanismo de sobrevivência sob domínio deste vegetal. Quando ocorre deiscência do fruto, a exposição ao vento inicia um processo de desidratação de toda a estrutura placentária onde despontam as fibras, fenômeno que permitirá a dispersão. As fibras são os verdadeiros veículos de transporte das sementes e estas, apresentando o máximo teor de umidade pelo fato de, possivelmente não haver passado pelo processo de secagem quando atingiram a maturação fisiológica, serão conduzidas para o ambiente onde, uma vez depositadas, germinarão. A hidratação, nas circunstâncias testadas não demonstrou influir na emergência, a despeito dos resultados favoráveis verificados nas primeiras seis horas de tratamento, explicação que fica inteiramente por conta da simples lavagem das sementes.

De qualquer modo é necessário destacar que a desidratação interferiu no vigor das sementes. Segundo as observações feitas por Nascimento et al., (2007) a secagem em sementes de Açaí causou retardamento no início da germinação, especialmente quando o teor de água foi reduzido para valor igual ou inferior a 30,3\%, algo bem próximo do verificado nesta pesquisa. Ao mesmo tempo é oportuno lembrar que, a rápida entrada de água em sementes que apresentam baixo teor de umidade pode desencadear alterações na conformação e estrutura do sistema de membranas das células que podem ser transitórias ou permanentes, dependendo da intensidade dos danos, conforme demonstrado por Hoekstra et al. (1999).

Acerca da emergência total os valores se mostraram elevados independentemente da condição da semente ou dos procedimentos de reidratação. Tais valores se assemelham àqueles obtidos por Silva et al., (2009), onde sementes de flor de seda na primeira contagem variaram entre 23 e 66\%, enquanto, a amplitude da germinação total esteve entre 48 e $75 \%$. É possível admitir que a desidratação da semente não determinou destruição de organelas como pode ocorrer nestas circunstâncias, até porque o processo natural de secagem, pela simples exposição ao ambiente, permitiu a manutenção de valores ainda elevados de umidade, próximos de $40 \%$, situação que não afetou a emergência total. De igual modo, a diversidade genética serve de recurso como explicação para o comportamento diferenciado. As características de emergência, fitomassa seca total de plântula e germinação são as que mais contribuem para a divergência genética em genótipos de $C$. procera (Almeida et al., 2017).

De acordo com Abdul-Baki (1980), durante a embebição, o sistema de membranas das sementes reorganiza-se, readquirindo o controle da permeabilidade, processo este que, ocorrendo no menor período de tempo possível poderá reduzir a perda de lixiviados para o meio externo. No caso em tela a emergência, independentemente da situação da semente, recém colhida, desidratada ou ainda submetida à hidratação, o valor mínimo ultrapassou os $80 \%$, não sendo acolhida pela reidratação. No açaí a redução do teor de água a valores abaixo de 30,3\% promove redução progressiva na germinação e vigor das sementes, de modo tal que ao atingirem $15,1 \%$ de teor de água, as sementes não mais germinaram (Nascimento et al., 2007). 
A redução do teor de água para valores inferiores a $45 \%$ prejudica a germinação de sementes em espécies de fruteiras nativas do gênero Eugenia da família Myrtaceae, que perderam a capacidade germinativa quando o teor de água foi inferior a 15\% (Delgado \& Barbedo, 2007). A secagem em sementes de soja com teor de água acima de 30\% provoca danos de membrana que diminuem a qualidade fisiológica das sementes (Silva et al., 2007). As sementes de Cynometra bauhiniifolia, importante fabaceae da Amazônia, são dispersas com alto grau de umidade $(54,1 \%)$ e tem a viabilidade comprometida quando desidratadas. O teor de água crítico situou-se na faixa de 46,6 \% a 41,4\%, enquanto grau de umidade letal ficou em $28,2 \%$ quando submetidas à secagem, em estufa, com circulação de ar (Nazario et al., 2008).

\section{Altura e Profundidade da Raiz}

A secagem das sementes impôs restrição na altura das plântulas, sendo as mesmas inferiores àquelas obtidas em sementes recém colhidas, independentemente da reidratação, não se registrando qualquer efeito daquele processo no parâmetro avaliado (Tabela 2). A diferença em altura entre plântulas oriundas de sementes recém colhidas ou desidratadas, independentemente da reidratação variou em torno de $27 \%$. O sistema radicular não foi afetado pela condição da semente nem tampouco pelo nível de hidratação, não chegando a atingir o limite de profundidade das bandejas de poliestireno expandido, cerca de $6,0 \mathrm{~cm}$, demonstrando a viabilidade do elastecimento do prazo no transplantio das mudas.

Tabela 2 - Médias para altura, profundidade da raiz, massa fresca da parte aérea e da raiz das plântulas de Flor de Seda (Calotropis procera), em sementes recém colhidas e desidratadas, com diferentes tempos de hidratação. Teresina/Piaui, 2018.

\begin{tabular}{|c|c|c|c|c|c|}
\hline \multirow[t]{3}{*}{ Tipo de semente } & \multicolumn{5}{|c|}{ Hidratação (horas) } \\
\hline & 00 & 02 & 04 & 06 & 08 \\
\hline & \multicolumn{5}{|c|}{ Altura $(\mathrm{cm})$} \\
\hline Recém colhida & $5.6450 \mathrm{aA}$ & $5.7600 \mathrm{aA}$ & $5.9250 \mathrm{aA}$ & $5.7850 \mathrm{aA}$ & $5.9200 \mathrm{aA}$ \\
\hline \multirow[t]{2}{*}{ Desidratada } & $4.4000 \mathrm{bA}$ & $4.2150 \mathrm{bA}$ & $4.1250 \mathrm{bA}$ & $4.2250 \mathrm{bA}$ & $4.1250 \mathrm{bA}$ \\
\hline & \multicolumn{5}{|c|}{$\begin{array}{l}\text { Profundidade } \\
\text { da raiz }(\mathrm{cm})\end{array}$} \\
\hline Recém colhida & $4.4300 \mathrm{aA}$ & $4.5200 \mathrm{aA}$ & $4.6300 \mathrm{aA}$ & $4.3350 \mathrm{aA}$ & $4.4300 \mathrm{aA}$ \\
\hline \multirow[t]{2}{*}{ Desidratada } & $4.5150 \mathrm{aA}$ & $4.5500 \mathrm{aA}$ & $4.6000 \mathrm{aA}$ & $4.2500 \mathrm{aA}$ & $4.1600 \mathrm{aA}$ \\
\hline & \multicolumn{5}{|c|}{$\begin{array}{c}\text { Massa parte } \\
\text { aérea }\end{array}$} \\
\hline Recém colhida & $0.5750 \mathrm{aA}$ & $0.5228 \mathrm{aA}$ & $0.5223 \mathrm{aA}$ & $0.5210 \mathrm{aA}$ & $0.5635 \mathrm{aA}$ \\
\hline \multirow[t]{2}{*}{ Desidratada } & $0.2425 \mathrm{bA}$ & $0.2175 \mathrm{bA}$ & $0.2225 \mathrm{bA}$ & $0.2100 \mathrm{bA}$ & $0.1850 \mathrm{bA}$ \\
\hline & \multicolumn{5}{|c|}{ Peso da raiz } \\
\hline Recém colhida & $0.3198 \mathrm{aA}$ & $0.3815 \mathrm{aA}$ & $0.3758 \mathrm{aA}$ & $0.3485 \mathrm{aA}$ & $0.3773 \mathrm{aA}$ \\
\hline Desidratada & $0.1925 \mathrm{bA}$ & $0.1950 \mathrm{bA}$ & $0.1925 \mathrm{bA}$ & $0.1950 \mathrm{bA}$ & $0.1775 \mathrm{bA}$ \\
\hline
\end{tabular}

Médias seguidas de mesma letra minúscula na coluna e maiúscula na linha, não diferem entre si, ao nível de 5\% de probabilidade, pelo Teste de Tukey. Fonte: Elaborada pelos autores, UFPI, Teresina-PI (2018).

\section{Massa Fresca da Parte Aérea e da Raiz}

$\mathrm{O}$ processo de secagem das sementes prejudicou drasticamente o peso da matéria fresca da parte aérea quando comparada às plântulas obtidas de sementes recém colhidas, com médias variando entre 140 e $210 \%$ enquanto a reidratação não contribuiu para a elevação destas diferenças nem tampouco na recuperação das mesmas (Tabela 2). Acerca da massa fresca da raiz, a desidratação das sementes provocou uma redução entre 60 e 120\%, sem registro de interferência da reidratação. Em guabiraba (Campomanesia pubescens), espécie classificada como recalcitrante, a redução do teor de água de 35 para $4 \%$ 
acarretou aumento no número de plântulas anormais (Dousseau et al., 2011; Nascimento et al. 2007) observaram que a desidratação crescente provocou redução do comprimento e da massa de matéria seca de plântulas de açaí

Ainda a respeito da secagem Hong e Ellis, (1992), consideram que as sementes que toleram dessecação parcial devem ser observadas além dos níveis máximo e mínimo suportáveis, o grau de umidade letal para cada espécie, tendo em vista a variação da sensibilidade à dessecação constituir-se atributo até, em diferentes lotes da mesma espécie (King \& Roberts, 1979; Eira et al., 1994).

\section{Considerações Finais}

Sementes recém colhidas apresentam teor de umidade em torno de $70 \%$ e desidratadas por 48 horas próximo de $35 \%$. Quando reidratadas, ainda ocorre, nos dois casos, ganho de umidade respectivamente de 18,13 e 43,33 \%. A reidratação melhora o vigor das sementes recém colhidas não influindo nas desidratadas e não interferindo na emergência total que esteve próxima de $90 \%$. A secagem apenas não influiu na profundidade da raiz, prejudicando outrossim, altura, massa fresca da parte aérea e raiz, em valores entre 27 e $210 \%$.

Tendo como pressuposto a grande variabilidade genotípica presente, tácito reflexo da ausência de manipulação genética do material, alvitra-se aprofundamento nos estudos envolvendo levantamento de novos genótipos, biologia floral, métodos de produção de mudas, possibilitando o cultivo em escala comercial.

\section{Referências}

Abdul-Baki, A. A (1980). Biochemical aspects of seed vigor. HortScience, Alexandria, 15(6), 765-71.

Akhtar, N., Malik, A., Ali, S. N., \& Kazmi, S. U. (1992). Proceragenin, and antibacterial cardenolide from Calotropis procera. Phytochemistry, 3(8), $2821-24$.

Almeida, I. B de, Dutra, W. F., Ramos, J. P. C., Bruno, R. de L. A., \& Alves, E. U. (2017). Diversidade genética entre genótipos de Calotropis procera (Ait.) W. T. Aiton em função da qualidade fisiológica das sementes. ReCaatinga, Mossoró, 30(4), 912-9.

Arya, S. \& Kumar, L. (2005). Antiinflamatory efficacy of extracts of latex of Calotropis procera against different mediators of inflammation. Mediators of Inflammation, 4, 228-32.

Atencio, L., Colmenares, R., Ramírez, M. V., Marcano, D. (2003). Tratamientos pregerminativos en acacia San Francisco (Peltophorum pterocarpum) Fabaceae. Revista da Faculdade de Agronomia, Luz, 20, 63-71.

Baudet, L. M. L., Villela, F. A., Cavariani, C. (1999). Princípios de secagem. Seed News, Pelotas-RS, n.10, $20-7$.

Brasil. (2009). Ministério da Agricultura, Pecuária e Abastecimento. Regras para análise de sementes. Ministério da Agricultura, Pecuária e Abastecimento. Secretaria de Defesa Agropecuária. - Brasília: Mapa/ACS, 399.

Carvalho, N. M., \& Nakagawa, J. (2000). Vigor de sementes. In: Carvalho, N. M., \& Nakagawa, J. (Eds.). Sementes: ciência, tecnologia e produção. (4a ed.), FUNEP. 224-42.

Chin, H. F., Hor, Y. L., \& Lassim, M. B. (1989). Identification of recalcitrant seeds. Seed Science and Technology, Zurich, 12, 429-36.

Corrêa, P. C., Afonso, P. C. A, Jr. (1999). Uso do teste de condutividade elétrica na avaliação dos danos provocados por diferentes taxas de secagem em sementes de feijão. Revista Brasileira de Produtos Agroindustriais, 1(1), 21-6.

Costa, C. J., Villela, F. A., Bertoncello, M. R., Tillmann, M. A. A., \& Menezes, N. L. (2008). Pré-hidratação de sementes de ervilha e sua interferência na avaliação do potencial fisiológico. Revista Brasileira de Sementes, 30(1), 198-207.

Delgado, L. F., \& Barbedo, C. J. (2007). Tolerância à dessecação de sementes de espécies de Eugenia. Pesq. agropec. bras., 42(2), $265-72$.

Dousseau, S., Alvarenga, A. A., Guimarães, R. M., Lara, T. S., Custódio, T. N., \& Chaves, I. S. (2011). Ecofisiologia da germinação de sementes de Campomanesia pubescens. Ciência Rural, 41(8), 1362-68.

Eira, M. T. S., Salomão, A. N., Cunha, R., Carrara, D. K., \& Mello, C.M.C. (1994). Efeito do teor de água sobre a germinação de sementes de Araucaria angustifolia. Revista Brasileira de Sementes, 16(1), 71-5.

Fernandes, F. C, Jr., Camerini, N. L., Fonseca, F. C. E., Fonseca, G. P., \& Nascimento, J. W. (2008). Qualidade do leite produzido por cabras alimentadas com níveis crescentes de feno de flor de seda. Revista Educação Agrícola Superior. Associação Brasileira de Educação Agrícola Superior- ABEAS, 23(1), 64-70. 
Freitas, C. D., Oliveira, J. S., Miranda, M. R., Macedo, N. M., Sales, M. P., Villas-Boas, L. A., \& Ramos, M. (2007). Enzymatic activities and protein profile of latex from Calotropis procera. Plant physiology and biochemistry: PPB, 45(10-11), 781-9. https://doi.org/10.1016/j.plaphy.2007.07.020.

Garcia, D. C., Barros, A. C. S. A., Peske, S. T., Menezes, N. L. (2004). A secagem de sementes. Ciência Rural, v.34(2), 603-8.

Gil, A. C. (2008). Como elaborar projetos de pesquisa. (4a ed.), São Paulo: Atlas.

Heydecker, W., Higgins, J., Gulliver, R. L. (1973). Accelerated germination by osmotic seed treatment. Nature, London, v.246(5427), p.42-4.

Hoekstra, F. A., Golovina, E. A., Van, A. C. A., Hemminga, M. A. (1999). Imbibitional leakage from anhydrobiotes. revisited. Plant, Cell and Environment, Oxford, v.22, 1121-31.

Hong, T. D., Ellis, R. H. (1992). Optimum air-dry seed storage environments for Arabica coffee. Seed Science and Technology, Zurich, v.20, 547-60.

Instituto Hórus - Instituto Hórus de Desenvolvimento e Conservação Ambiental. The Nature Conservancy, www.institutohorus.org.br/download /fichas/calotropis_procera.htm/>.

Kareem, S. O., Akpan, I., Ojo, O. P. (2008). Antimicrobial Activities of Calotropis procera on Selected Pathogenic Microorganisms. African Journal of Biomedical Research. v.11, 105-10.

ISSN 1119 - 5096 @ Ibadan Biomedical Communications Group.

Khan, A. Q. \& Malik, A. (1989). Asteroids from Calotropis procera. Phytochemistry, v.28(10), 2859-61.

King, M. W. \& Roberts, E. H. (1979). The storage of recalcitrant seeds: achievements and possible approaches. Rome: IBPGR, 96.

Lin, S. S. (1990). Alterações na lixiviação eletrolítica, germinação e vigor da semente de feijão envelhecida sob alta umidade relativa do ar e alta temperatura. Revista Brasileira de Fisiologia Vegetal, v.2, 1-6.

Little, E. L, Jr., Woodbury, R. O., Wadsworth, F.H. (1974). Trees of Puerto Rico and the Virgin Islands, 2. Agric. Handb, 449. U.S. Departament of Agriculture, Washingtion, DC. 1024.

Miranda, L. C., Da Silva, W. R., Cavariani, C. (1999). Secagem de sementes de soja em silo com distribuição radial do fluxo de ar. I. Monitoramento físico. Pesq agropec bras, Brasília, v.34(11), 2097-108.

Moreira, E. C. F., Viana, B. L. (2007). Flor de seda: considerações gerais. http://www.cca.ufpb.br/lavouraxerofila/pdf/fs.pdf.

Nascimento, W. M. O., Novembre, A. D. L. C., Cicero, S. M. (2007). Consequências fisiológicas da dessecação em sementes de açaí (Euterpe oleracea Mart.). Revista Brasileira de Sementes, vol. 29(2), 38-43.

Nascimento, W. M. (1998). Condicionamento osmótico de sementes de hortaliças: potencialidades e implicações. Horticultura Brasileira, v.16, 106-9.

Nazario, P., Ferreira, S. A. N., Rebouças, E. R. (2008). Germinação na Cynomelia bauhinifolia, Benttar (jutairana) em função do dessecamento e da manutenção sob condição úmida. Acta Agronomica, n. 38(3), 439-44.

Peske, S. T., Barros, A. C. S. A. (1997). Produção de sementes de arroz. In: Peske, S. T., Nedel, J. L., Barros, A. C. S. A. Produção de arroz irrigado Pelotas: UFPel. 351-412.

Popinigis, F. (1985). Fisiologia de sementes. Brasília: AGIPLAN, 289.

Queiroga, P., Durán, J. M., Santos, J. W., Queiroga, D. A. N. (2009). Qualidade de sementes de algodão submetidas ao condicionamento hídrico. Revista Agro Ambiente On-line, v.3(1), 31-5. Centro de Ciências Agrárias - Universidade Federal de Roraima, Boa Vista, RR www.agroambiente.ufrr.br.

Ramos, M. V., Bandeira, G. P., Freitas, C. D. T., Nogueira, N. A. P., Alencar, N. M. N., Sousa, P. A. S., Carvalho, A. F. U. (2006). Latex constituents from Calotropis procera (R. Br.) display toxicity upon egg hatching and larvae of Aedes aegypti (Linn.). Mem Inst Oswaldo Cruz, Rio de Janeiro, v.101(5), 503-10.

Rangel, E. S. \& Nascimento, M. T. (2011). Ocorrência de Calotropis procera (Ait.) R. Br. (Apocynaceae) como espécie invasora de restinga. Acta Botânica Brasílica, Feira de Santana, v.25(3).

Rosa, S. D. F., Pinho, E. R. V., Vieira, M. G. G. C., Vieira, R. D. (2000). Eficácia do teste de condutividade elétrica para uso em estudos de danos de secagem em sementes de milho. Revista Brasileira de Sementes, v.22(1), 54-63.

Rosseto, C. A. V., Novembre, A. D. L. C., Marcos, J. F., Silva, W. R., Nakagawa, J. (1997). Comportamento da semente de soja durante a fase inicial do processo de germinação. Scientia Agricola, v.54(1/2), 106-15.

Silva, P. A., Diniz, K. A., Oliveira, J. A., Pinho, E. R. (2007). Análise fisiológica e ultra-estrutural durante o desenvolvimento e a secagem de sementes de soja. Revista Brasileira de Sementes, v.29(2), 15-22.

Silva, J. R.: Medeiros, M. A. A., Nascimento, I. J. B., Ribeiro, M. C. C., Nunes, G. H. S. (2009). Temperatura e substrato na germinação de sementes de florde-seda. Caatinga (Mossoró,Brasil), v.22(1), 175-9.

Souto, P. C., Sales, F. C. V., Souto, J. S., Santos, R. V., Sousa, A. A. (2008). Biometria de frutos e número de sementes de Calotropis procera (Ait.) R. Br. no semiárido da Paraíba. Revista Verde (Mossoró - RN - Brasil), v.3(1), 108-13.

Taiz, L., Zeiger. E. (1998). Plant physiology. Sunderland: Sinauer Associates, (2a ed), 793. 
Research, Society and Development, v. 10, n. 17, e255101724898, 2021

(CC BY 4.0) | ISSN 2525-3409 | DOI: http://dx.doi.org/10.33448/rsd-v10i17.24898

Vaz, F. A. et al. (1998). Avaliação do potencial forrageiro do algodão de seda (Calotropis procera) I - Consumo e Digestibilidade da MS In: Reunião Da Sociedade Brasileira De Zootecnia, 35., Botucatu: Anais da Sociedade Brasileira de Zootecnia. CD-ROM.

Vieira, R. D., Scappa, A. N., Bittencourt, S. R. M., Panobianco, M. (2004). Electrical conductivity of the seed soaking solution and soybean seedling emergence. Scientia Agrícola, v.61(2), 164-8. 